Article

\title{
Encapsulation of Antihypertensive Peptides from Whey Proteins and Their Releasing in Gastrointestinal Conditions
}

\author{
Yolanda Alvarado ${ }^{1}$, Claudia Muro ${ }^{1, *}$, Javier Illescas ${ }^{1}{ }^{(0)}$, María del Carmen Díaz ${ }^{1}$ and \\ Francisco Riera ${ }^{2}$ \\ 1 Tecnológico Nacional de México/Instituto Tecnológico de Toluca, Toluca C.P 52140, Mexico; \\ yalvaradop@toluca.tecnm.mx (Y.A.); fillescasm@toluca.tecnm.mx (J.I.); mdiazn@toluca.tecnm.mx (M.d.C.D.) \\ 2 Departament of Chemical Engineering and Envioronmental Technology, University of Oviedo, \\ C. P. 33006 Oviedo Asturias, Julián Clavería 8, Spain; far@uniovi.es \\ * Correspondence: cmurou@toluca.tecnm.mx; Tel.: +527227096994; Fax: +527222087224
}

Received: 25 February 2019; Accepted: 22 April 2019; Published: 27 April 2019

check for updates

\begin{abstract}
Antihypertensive peptide fraction from whey protein hydrolysate $<3 \mathrm{kDa}$ (measured as angiotensin-converting enzyme (ACE) activity \%) was isolated and encapsulated into three composite materials: alginate-collagen, alginate Arabic gum, and alginate-gelatin. The release behavior of peptide fraction from capsules was analyzed according to the encapsulation material efficiency, the characteristics of the capsules, and the released antihypertensive peptides during gastrointestinal digestion. The highest encapsulation efficiency was found in capsules of alginate Arabic gum (95\%). In this case, the released peptides incremented their ACE activity ( $85 \%)$ after the digestion process, with respect to the initial ACE activity (74\%). Whey antihypertensive fraction revealed five peptide sequences; however, other amino acid sequences were released from digested capsules. Protein databases confirmed some antihypertensive sequences indicating the peptides content from $\beta$-Lg and $\alpha$-La. Consequently, new peptides could be revealed from whey antihypertensive fraction.
\end{abstract}

Keywords: antihypertensive peptides; encapsulation; composite materials; peptides releasing; gastrointestinal conditions

\section{Introduction}

Milk protein hydrolysates and their peptides are considered active molecules with biological properties to control and prevent chronic diseases, such as hypertension, obesity, diabetes, cancer, and oxidative stress [1,2]. Their benefits have been extensively tested in different reports, which has promoted their application in the elaboration of different products. Specifically, whey peptides are used as ingredients in the preparation of foods with different health benefits and they are also utilized to increment the functional properties of different types of foods or to provide new characteristics to them [3]. However, their health benefits in vivo are strongly affected, because these substances present a short lifetime, little stability, and severe degradation in gastrointestinal conditions [4].

Clinical applications of milk peptides have also been limited due to variable or poor effects when administered orally. Some of the causes are their variable instability and their fast degradation within the gastrointestinal tract (GIT) by digestive enzymes. Therefore, the active molecules exert a partial health effect, and thus, their target stimulus is achieved also in limited form $[5,6]$.

In addition, hydrolyzed milk proteins and peptides may cause products with characteristics not favorable for their use, such as the alteration of their sensorial properties, texture, and color. The origin of these problems is attributed to the low bioavailability of molecules, their bitter taste, their hygroscopicity, or their probability of interacting with the food matrix [7]. 
Currently, numerous studies have demonstrated that some of these limitations may be overcome by the encapsulation of active molecules. Some of the advantages of this method are: (i) to preserve and to extend the activity, as well as to protect from the harsh environments such as heat, moisture, air, light, and intestinal enzymes; (ii) to retain its shelf life and to avoid the alteration of their chemical structure during the processing of a product; and (iii) to control the delivery of the active substance to a specific site [4].

Advances on encapsulation technology have led to the develop of an ever-increasing number of composite materials to prepare different carriers for containing and releasing active substances, namely, hydrogels, emulsions, nanoparticles, microspheres, and liposomes. They have been reported as a vehicle for different food ingredients like pigments, vitamins, fatty acids, antioxidants, and minerals [8]. However, little information about the encapsulation of milky peptides and their releasing mechanisms can be found in the literature. Studies on this topic demand different aspects that would fulfill their application and commercialization. For this purpose, it is necessary to demonstrate that biological molecules can reach the gastric tract without further degradation and can be released in the form of peptide fragments with considerable activity to ensure its action and benefits in the organism.

Research on this subject were reported by Yu et al. [9], who studied the encapsulation of bovine-serum albumin (BSA) into particles based on materials such as chitosan, alginate, and pectin. In addition, Yang et al. [10] tested the effect of the encapsulation of whey protein hydrolysates in capsules of maltodextrin and $\beta$-ciclodextrin. On the other side, Kavianinia et al. [11] analyzed the encapsulation of BSA in chitosan microspheres, and Ma et al. [12] used microspheres of sodium alginate to encapsulate whey protein hydrolysates. The most important results from these reports confirmed that peptide encapsulation improves the stability of active molecules and reduces their bitter taste.

Recent studies have also revealed that whey peptides encapsulation on nanoliposome carriers of soya lecithin [13], microspheres of sodium alginate [14], and $\beta-\mathrm{Lg}$ derived peptides in Poly Lactic-co-Glycolic Acid (PLGA) nanoparticles [15] could help release active molecules and improve their stability and action. Furthermore, some reports, such as Gómez-Mascaraque et al. [16], Bokkihim et al. [17], and Giroux et al. [18] employed simulated gastric fluid conditions to analyze peptides release behavior. They found that encapsulation offers protection to the active molecules and mainly can control the release of peptides; however, these aspects depend on the type of material of the carrier, the preparation processing techniques, the chemistry of the peptides, and their size.

Nonetheless, to have some evidence about the benefits on the encapsulation of active molecules is not sufficient and more research is needed to increase the amount of information on this topic. Essentially, it is necessary to expand research on the release of whey active molecules during the digestion process in order to provide valuable data on the efficiency of peptides encapsulation technology.

The present work describes the encapsulation of antihypertensive peptides derived from whey protein hydrolysate and analyzes the release of these peptides in in vitro conditions.

The effects of encapsulation on the preservation of antihypertensive activity and controlled release of whey peptides were studied in model conditions of simulated gastrointestinal digestion. Composite biopolymers based on the sodium alginate matrix and filler materials, such as gelatin, Arabic gum, and collagen were tested as encapsulating materials.

\section{Materials and Methods}

\subsection{Materials}

The following reagents were supplied by Merck (Darmstadt, Germany). Sodium alginate (SA) medium viscosity; Arabic gum (AG) from the acacia tree (branched polysaccharide); calcium L-lactate hydrate $\geq 98 \%$ (calc. based on dry substance, KT); N-Hippuryl-His-Leu hydrate powder, $\geq 98 \%$ HPLC grade; angiotensin converting enzyme from rabbit lung $\geq 2.0$ units/mg protein; ethyl acetate anhydrous, 99.85\%; potassium phosphate dibasic, reagent grade $\left(\mathrm{K}_{2} \mathrm{HPO}_{4}\right)$. 
Gelatin (GE) alkaline-processed (type B) from bovine skin and collagen (CO) from calfskin were obtained from Colloidal Duche S.A. Toluca, México. Bovine cheese whey was kindly supplied by a dairy industry in Mexico and the protein concentration in whey was determined as $11.5 \pm 0.5 \mathrm{~g} / \mathrm{L}$.

Bacillus subtilis (free living strain 05) was obtained from the Research Laboratory of Environmental Engineering from the Institute Technologic of Toluca, Toluca, México. One part of this strain was placed in $100 \mathrm{~mL}$ of whey milk ( $11 \mathrm{~g} / \mathrm{L}$ of protein) and it was incubated for $24 \mathrm{~h}$ at $37^{\circ} \mathrm{C}$. The Bacillus subtilis culture was subsequently used in all experiments of whey protein hydrolysis.

\subsection{Whey Protein Hydrolysis}

Whey protein concentrate (WPC), with $84 \%$ protein and $10 \%$ lactose, was obtained by ultrafiltration processes (UF) of bovine whey samples using cross-flow polymeric membranes (15 kDa cut-off and $0.020 \mathrm{~m}^{2}$ effective membrane area).

WPC was hydrolyzed by direct fermentation using B. subtilis biomass. The hydrolysis processes were carried out in Erlenmeyer flasks. In each test, $100 \mathrm{~mL}$ of WPC were incubated with B. subtilis biomass $\left(10 \% v / v ; 2.6 \times 10^{8} \mathrm{cfu} / \mathrm{mL}\right)$.

The flasks were sealed and put under orbital stirring at $200 \mathrm{rpm}$ at $50{ }^{\circ} \mathrm{C}$, and then underwent hydrolysis for $6 \mathrm{~h}$ (Alvarado et al., 2018). Proteolytic action was stopped by separating the free cells. The obtained samples were centrifuged at 10,000 rpm for $5 \mathrm{~min}$; afterwards, supernatants were separated and identified as whey protein concentrate hydrolysate (WPCH) products. WPCH products were frozen and stored at $-10{ }^{\circ} \mathrm{C}$ until further analysis.

\subsection{Fractionation of Hydrolysate Product}

The WPCH product was first fractionated by a polymeric MICROZA membrane with a molecular weight cut-off (MWCO) of $3 \mathrm{kDa}$ (Pall Corporation). The whey protein concentrate hydrolysate permeate (WPCHP) fractions $<3 \mathrm{kDa}$ and the whey protein concentrate hydrolysate retained (WPCHR) fractions were collected during the filtration. Subsequently, the WPCHP was fractionated $(20 \mathrm{mg} / \mathrm{mL})$ by the gel filtration chromatography technique, using a Waters Liquid Chromatography System (USA) with a dual pump (Waters model 1525) and a Sephadex G-25 column $(2.5 \mathrm{~cm} \times 70 \mathrm{~cm})$. Fractions were collected at the flow rate of $0.6 \mathrm{~mL} / \mathrm{min}$ and the absorbance, at $220 \mathrm{~nm}$, was monitored. At last, each fraction was lyophilized and stored at $-10^{\circ} \mathrm{C}$ until further analysis.

\subsection{Determination of ACE Inhibitory Activity of Whey Peptide Fractions}

Angiotensin-converting enzyme (ACE) inhibitory action was determined in peptide fractions, according to the method of Cushman and Cheung [19], with some modifications. The following solutions were used in the ACE quantification: (i) Histidyl-hipuryl leucine (HHL) (substrate of ACE), was prepared by employing $54 \mathrm{mg}$ dissolved in $25 \mathrm{~mL}$ of dibasic potassium phosphate buffer solution $0.1 \mathrm{M}$, and $0.3 \mathrm{M}$ sodium chloride at $\mathrm{pH} 8.3$, resulting in a final $5 \mathrm{mM}$ concentration of HHL; (ii) ACE $(0.5 \mathrm{mg})$ was dissolved in $1 \mathrm{~mL}$ of glycerol solution, $50 \% v / v$; (iii) The sample solution (M) was prepared with $40 \mu \mathrm{L}$ of peptides sample, $100 \mu \mathrm{L}$ of HHL solution, and $40 \mu \mathrm{L}$ of ACE solution. The control solution (C) was prepared mixing $40 \mu \mathrm{L}$ of buffer solution, adding $100 \mu \mathrm{L}$ of HHL solution, and $40 \mu \mathrm{L}$ of ACE solution. Meanwhile, the blank solution (B) was prepared mixing $40 \mu \mathrm{L}$ of distilled water with $100 \mu \mathrm{L}$ of HHL solution, and $40 \mu \mathrm{L}$ of ACE solution. The obtained samples $\mathrm{M}, \mathrm{B}$, and $\mathrm{C}$ were centrifuged at $5000 \times g$ for $5 \mathrm{~min}$, and incubated at $37^{\circ} \mathrm{C}$ for $30 \mathrm{~min}$. After this time, the ACE enzyme was inactivated with the addition of $150 \mu \mathrm{L}$ of $\mathrm{HCl} 1 \mathrm{~N}$. After, $1 \mathrm{~mL}$ of ethyl acetate was added in each solution (A, B, and C), shaken in a vortex, and centrifuged for $10 \mathrm{~min}$ at $1541 \times g ; 750 \mu \mathrm{L}$ of the supernatant (organic phase) were taken and evaporated by heating them at $85^{\circ} \mathrm{C}$ for $15 \mathrm{~min}$. Then, $2000 \mu \mathrm{L}$ of distilled water were added to the residue with orbital stirring. Lastly, the absorbance, at $220 \mathrm{~nm}$, was measured for all samples, using a UV-Vis spectrophotometer LAMBDA 35 Perkin Elmer (Waltham, Massachusetts USA). 
Inhibition of ACE was expressed as a percentage of the residual ACE activity, which was calculated according to Equation (1).

$$
\text { ACE inhibitory activity }(\%)=(C-M) \times 100 /(C-B)
$$

where $\mathrm{C}$ is the absorbance of the control solution $\mathrm{C} ; \mathrm{M}$ is the absorbance in the sample; and $\mathrm{B}$ is the absorbance in the blank solution B.

The $\mathrm{IC}_{50}$ value (the concentration of inhibitor resulting in a 50\% reduction of ACE activity) was calculated by the regression analysis from the ACE inhibition curve obtained with increasing amounts of the inhibitor. The $\mathrm{IC}_{50}$ values were expressed as $\mathrm{ACE} \%$.

\subsection{Encapsulation of the Peptide Fractions}

Fractions with the highest ACE inhibitory activity were encapsulated in composite matrices of sodium alginate (SA) with Arabic gum (AG), collagen (CO), and gelatin (GE) as the filler materials, and also used as individual complementary constituents.

The encapsulating carriers SA-AG, SA-GE, and SA-CO were prepared as follows: AG, CO, or GE was dispersed in a SA solution $1.5 \%(\mathrm{p} / \mathrm{v})$ under stirring, followed by sonication for $15 \mathrm{~min}$. After, the hydrolysate fraction with the highest ACE inhibition was dispersed in each matrix, in a weight ratio of 4:1 at $30^{\circ} \mathrm{C}$. Capsules with different mixtures between the matrix and fractions were obtained by the extrusion method and dropped into calcium lactate 5\% wt. The obtained capsules were separated by decantation and washed with distilled water to eliminate the lactate excess.

The morphology and porosity of the encapsulating matrices were determined by means of scanning electron microscopy (SEM), employing a JEOL JSM-6610LV microscope. Surface area, pore volume and pore-size distribution was evaluated by Brunauer, Emmett and Teller (BET) method, using a analyzer BELSORP-aqua3, BEL Japan, Inc.

The entrapment efficiency of whey peptides from $\mathrm{f} 4$ fraction in the encapsulated matrices SA-CO, SA-AG, and SA-GE was determined by dissolving $50 \mathrm{mg}$ of capsules in $1 \mathrm{~mL}$ of methanol or an alkaline solution. This parameter was calculated as the encapsulation efficiency (\%) and it was defined as the ratio between the protein content of non-encapsulated peptides and the released peptides from the dissolved capsules. Finally, the protein content of the filtrate was measured by the Biuret method.

\subsection{Simulated Gastrointestinal Digestion of Encapsulated Peptide Fractions}

Kinetics of the released peptides from encapsulation was analyzed through in vitro studies under simulated gastrointestinal conditions (SGC) according to the protocols of the digestive phases reported by Minekus et al. [20]-1) Simulated salivary fluid (oral phase, SSF), 2) simulated gastric fluid (gastric phase, SGF), and 3) simulated intestinal fluid (duodenal phase, SIF).

The saliva fluid was obtained preparing a solution with $2.38 \mathrm{~g} \mathrm{Na} 2 \mathrm{HPO} 4,0.19 \mathrm{~g} \mathrm{KH}_{2} \mathrm{PO} 4$, and $8 \mathrm{~g}$ $\mathrm{NaCl}$ dissolved in $1 \mathrm{~L}$ of distilled water. The $\mathrm{pH}$ was adjusted to $\mathrm{pH} 7$ and $\alpha$-Amylase (EC 3.2.1.1) was added to the mixture to obtain $200 \mathrm{U}$ enzyme activity. Gastric fluid was obtained by mixing $0.31 \%$ of pepsin enzyme, EC 3.4.23.1 and 0.03 M NaCl. The $\mathrm{pH}$ value was adjusted to $\mathrm{pH} 1.5$ with $\mathrm{HCl} 1 \mathrm{M}$. Intestinal fluid was prepared dissolving $0.05 \mathrm{~g}$ of pancreatin and $0.3 \mathrm{~g}$ of porcine bile extract in $35 \mathrm{~mL}$ of $\mathrm{NaHCO}_{3} 0.1 \mathrm{M}$. The $\mathrm{pH}$ was adjusted to $\mathrm{pH} 6$ with $\mathrm{NaHCO}_{3} 0.1 \mathrm{M}$.

The in vitro gastrointestinal experiments were carried out in glass tubes, considering SSF, SGF, and SIF phases. In the SSF phase, $10 \mathrm{~mL}$ of saliva fluid were put in contact with encapsulated peptide fractions (50 capsules of each matrix) and free fractions equivalent to $4 \mathrm{mg} / \mathrm{mL}$. Samples were incubated at $37^{\circ} \mathrm{C}$, at a pH 7 for $10 \mathrm{~min}$, in a shaking incubator stirred at $150 \mathrm{rpm}$. Subsequently, the gastric phase was obtained from the digestion of gastric fluid solution $(10 \mathrm{~mL})$ and porcine pepsin $(2000 \mathrm{U} / \mathrm{mL})$. The mixture was incubated at $37^{\circ} \mathrm{C}$ and $\mathrm{pH} 3$ for $2 \mathrm{~h}$ in a shaking incubator at $150 \mathrm{rpm}$. The gastric digest fluid was mixed $(7.5 \mathrm{~mL})$ with porcine bile extract $(10 \mathrm{mM})$ and porcine pancreatin $(100 \mathrm{U} / \mathrm{mL}$ of trypsin activity), $1.25 \mathrm{~mL}$ of $120 \mathrm{mM} \mathrm{NaCl}$, and $1.25 \mathrm{~mL}$ of $5 \mathrm{mM} \mathrm{KCl}$. The $\mathrm{pH}$ of the mixture 
was adjusted to 7 with $\mathrm{NaOH} 1 \mathrm{M}$; the mixture was incubated for another $2 \mathrm{~h}$ at $37^{\circ} \mathrm{C}$, and stirred at $150 \mathrm{rpm}$. To finish the gastric process, in the last phase, the protease inhibitor Pefabloc ${ }^{\circledR}(1 \mathrm{mM})$ was added.

All of the digested products from each phase were centrifuged at $500 \times g$ for 15 min; then supernatants were collected and centrifuged at $10,000 \times g$ for 5 min for a further analysis. The non-digested capsules during the gastric process were suspended in acetic acid $(20 \% v / v)$ or $\mathrm{NaOH}(20 \% \mathrm{v} / \mathrm{v})$ to dissolve them. The ACE inhibitory activity, the concentration of proteins and the identification of amino acid sequences, released from both the encapsulated and the free peptides, were measured in each phase and matrix. The ACE was determined by the method described in Section 2.4, and the concentration of proteins was determined by the Biuret method.

\subsection{Analysis and Identification of Amino Acid Sequences from the Released Peptides in Simulated Gastrointestinal Digestion from the Encapsulated f4 Fraction}

Samples of released peptides, after each phase of the gastrointestinal digestion, were exposed to sequence identification by liquid chromatography and mass spectrometry.

The obtainment and identification of peptides was performed using a (RP-HPLC), Agilent 1200 series Reverse Phase Liquid chromatography-mass spectrometry (LC/MS system), coupled to an Agilent 6500 Series Q-TOF LC/MS system, Quadrupole-Time-of-flight liquid. Samples $(10 \mu \mathrm{L})$ were injected into a Zorbax Eclipse C18 $(4.6 \mathrm{~mm} \times 250 \mathrm{~mm}, 5 \mu \mathrm{m})$ column, as the eluting program two mobile phases were employed, water containing $0.1 \%$ trifluoric acetic acid (TFA) (phase A, $30 \mathrm{~min}$ ) and acetonitrile $35 \%$ with $0.1 \%$ TFA (phase B, $30 \mathrm{~min}$ ) at a flow rate of $2.0-2.5 \mathrm{~mL} / \mathrm{min}$, temperature of $95^{\circ} \mathrm{C}$ and pressure of 550 bar.

The obtained eluents were injected into the MS system. The MS analysis was performed in the positive ion mode for Auto LC/MS between 100 and $2500 \mathrm{~m} / \mathrm{z}$ range; and the target masses 1221 and 322 , respectively. The major peaks were selected to identify the peptide sequences employing the protein databases LC/MS Chemstation Software and Agilent MassHunter Workstation Software-Qualitative Analysis (Santa Clara, CA, US) (detection limit range $0.01 \mathrm{mg} / \mathrm{L}$ ), allowing the identification of the peptides. The used parameters for both programs followed the next sequence: selection of the peptide charge $(1+, 2+, 3+)$; tolerances of 1.0-1.5 Da for both the precursor and fragments ions; and the use of trypsin as proteases. The obtained sequences were also compared with peptide from whey proteins from the universal protein database resource (UniProt database) [21].

\subsection{Statistical Analysis}

All determinations were performed in triplicate. The experimental data were evaluated using the analysis of variance, followed by Duncan's new multiple range test. Statistical significance was used to evaluate the differences between means at a significance level of $p<0.05$.

\section{Results and Discussion}

\subsection{ACE Inhibitory Activity of Hydrolysate Fractions}

The hydrolysis of WPC after $6 \mathrm{~h}$ of proteolytic action of $B$. subtilis was confirmed by means of the hydrolysis degree (DH\%). The hydrolysate product WPCH showed a DH range of 35\%-40\%. Moreover, WPCHP and WPCHR fractions from membrane filtration ( $3 \mathrm{kDa})$ showed protein concentrations of $4.18 \mathrm{mg} / 100 \mathrm{~mL} \pm 0.8$ and $1.61 \pm 0.8 \mathrm{mg} / 100 \mathrm{~mL}$, respectively. This means, that a higher content of short peptides <3 KDa were present in fractions WPCHP; meanwhile, 4 fractions, f1-f4 from WPCHP, were obtained as result of the gel filtration chromatography, which corresponded to fractions $\mathrm{f} 1$, from 50 to $80 \mathrm{~min}$; f2, from 120 to $130 \mathrm{~min}$; f3, from 200 to $210 \mathrm{~min}$; and f4, from 220 to $250 \mathrm{~min}$.

In the case of the ACE inhibition percentage (\%) from $\mathrm{f} 1$ to $\mathrm{f} 4$, Figure 1 shows data on the biological activity of these fractions. From this figure, it is shown that $\mathrm{f} 1-\mathrm{f} 4$ exhibited a high ACE-inhibitory effect. The non-fractioned WPCHP presented $45.67 \pm 1.2 \%$; whereas fractions $\mathrm{f} 1-\mathrm{f} 4$ showed $56 \%-80 \%$ 
of ACE inhibition. It is noteworthy that the ACE inhibitory activity from f4 was the highest, exhibiting a value of $80.65 \pm 1.5 \%$.

These results were attributed to WPC hydrolysis by the proteolytic action of serine protease and metalloprotease enzymes from B. subtilis [6], which resulted in a satisfactory release of ACE inhibitory peptides.

The highest ACE inhibitory activity from $\mathrm{f} 4$ was associated with the lowest molecular weight of the contained peptides, because of the presence of short peptide sequences, as well as the peptide structure with a specific amino acid composition.

Although several problems have been found for the identification of short peptides from hydrolyzed complexes [22], there is some information about the relationship between the short peptides and their ACE-inhibitory activity. Specifically, di- and tri-peptides are linked to ACE enzymes, because they are bonded to an active site [23,24].

The position of the amino acids within the sequence (at the $\mathrm{N}$ - or $\mathrm{C}$-terminal) and its adjacent residues, have also been recognized as important factors that affect ACE activity from peptides. ACE shows affinity to peptide sequences containing amino acids in the C-terminal, such as proline and leucine, and hydrophobic amino acids (or positively charged) such as phenylalanine, tryptophan, and tyrosine. Wu et al. [25] also found that the residue of the C-terminal tetrapeptide may determine the potency of ACE inhibition - with preference for tyrosine and cysteine in the first C-terminal position; histidine, tryptophan and methionine in the second; leucine, valine and methionine in the third; and tryptophan in the fourth position.

The occurrence of these amino acids in the released peptides from whey hydrolysis was currently confirmed by Alvarado et al. [6]. Whey protein produced from the hydrolysis process with B. subtilis enriched peptides with high content in amino acids residues as valine, leucine, tyrosine, phenylalanine, proline, arginine and isoleucine, and they were the principal contributors of ACE activity. Other obtained results on the production of ACE inhibitory peptides by enzymatic action of B. subtilis were similar to previous reports from protein hydrolysis from marine organisms [14,23].

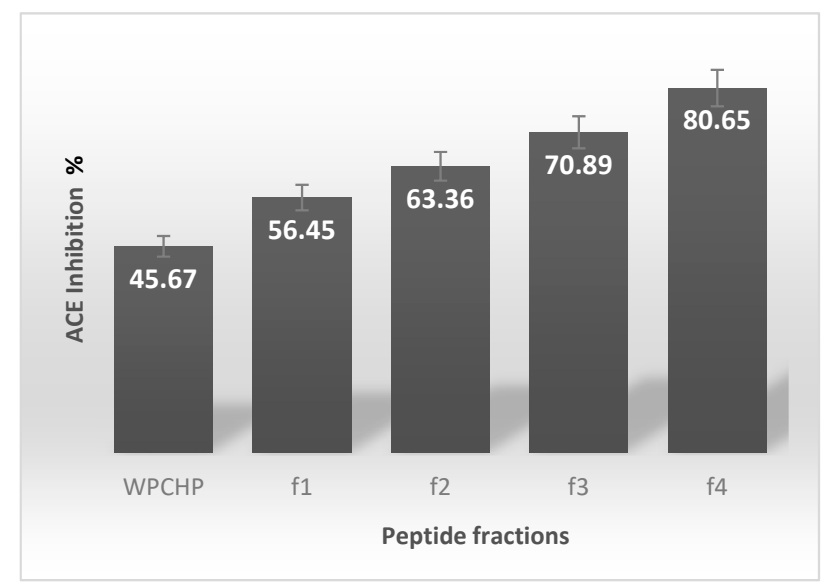

Figure 1. Angiotensin-Converting Enzyme inhibition \% of whey protein concentrate hydrolysate permeate (WPCHP) and peptide fractions (f1-f4) from gel filtration chromatography. Fractions correspond as follows: f1, from 50 to $120 \mathrm{~min}$; f2, from 120 to $180 \mathrm{~min}$; f3, from 200 to $210 \mathrm{~min}$; and f4, from 220 to $250 \mathrm{~min}$. Values are expressed as the average \pm SD of three independent determinations.

\subsection{Capsules Characteristics and Encapsulation Efficiency}

The obtained capsules SA-CO, SA-AG, and SA-GE, loaded with whey peptide f4, seemed very similar and had a spherical form with a diameter size of $1-2 \mathrm{~mm}$; however, pore dimensions and surface area presented important differences associated to the composite materials used in the encapsulation process. Moreover, these data were comparable with SA capsules. The obtained data are shown in Table 1. 
Table 1. Capsules pore dimensions and encapsulation efficiency.

\begin{tabular}{ccccc}
\hline Capsules & $\begin{array}{c}\text { Pore Volume } \\
\left(\mathbf{c m}^{\mathbf{3}} \mathbf{g}\right)\end{array}$ & $\begin{array}{c}\text { Surface Area } \\
\left(\mathbf{m}^{\mathbf{2}} \mathbf{g}\right)\end{array}$ & $\begin{array}{c}\text { Pore Diameter } \\
(\mathbf{n m})\end{array}$ & Encapsulation Efficiency $\mathbf{\%}$ \\
\hline SA & 0.0252 & 1.003 & 6.9 & 70 \\
SA-CO & 0.0019 & 1.405 & 5.5 & 90 \\
SA-AG & 0.0016 & 1.082 & 6.1 & 95 \\
SA-GE & 0.0018 & 1.95 & 3.8 & 80 \\
\hline
\end{tabular}

The SA-CO, SA-AG, and SA-GE capsules incremented the surface area in comparison with the individual SA capsule. The highest value was found for the SA-GE capsules, followed by SA-CO, and finishing with SA-AG. Therefore, a greater contact between gastric fluids and SA-GE capsules could be expected; this could cause an important capsule erosion and the release of peptides in shorter times. The filler materials also modified pore diameter. SA capsules showed high pore diameter, whereas their composite presented a reduced pore. This modification possibly improved the mechanical properties and the peptides retention, and prevented peptides to leak from capsules, because capsules of SA have displayed fragility and friability with higher pore sizes, which may also cause some fractures and disintegration of the material during the hydrolysis process.

In regard to encapsulation efficiency, SA-CO, SA-AG, and SA-GE presented higher values, ca. $85 \%-95 \%$. SA-AG capsules reached the highest efficiency, followed by SA-CO, and lastly, the SA-GE capsule. This result was associated with materials properties, such as their capacity of entrapment, their binding abilities and their interactions between peptides and f4 fraction. Specifically, AG is a highly branched heteropolymer consisting of sugars, which contains a small amount of protein, covalently linked to the carbohydrate chain. Its bind with SA (polysaccharide) could lead to low intermolecular interactions of $\mathrm{f} 4$ fraction; thus, the entrapment mechanism of SA-AG may be owed to its excellent film-forming property, providing a better trapping, and a much higher release ratio of $\mathrm{f} 4$ fraction. As for SA-CO and SA-GE capsules, the entrapment and release properties can be also attributed to their interactions with $\mathrm{f} 4$ fraction. Primarily, the obtained result with SA-GE capsules could be associated to the strong interactions with $\mathrm{f} 4$ fraction, since GE has a negative charge [26]. In addition, the formation of complexes due to the instability of $f 4$ fraction, and its interactions with SA matrix, could be also considered in the obtained data. The interactions of $f 4$ fraction with GE could also contribute to the transformation of $\mathrm{f} 4$ to other less stable forms, which also makes its releasing difficult, and thus lowers encapsulation efficiency.

The obtained SEM micrographs of the capsule surface complemented the last result. Figure 2 shows micrographs of SA-AG, SA-CO, and SA-GE capsule surfaces loaded with f4 peptide fraction.
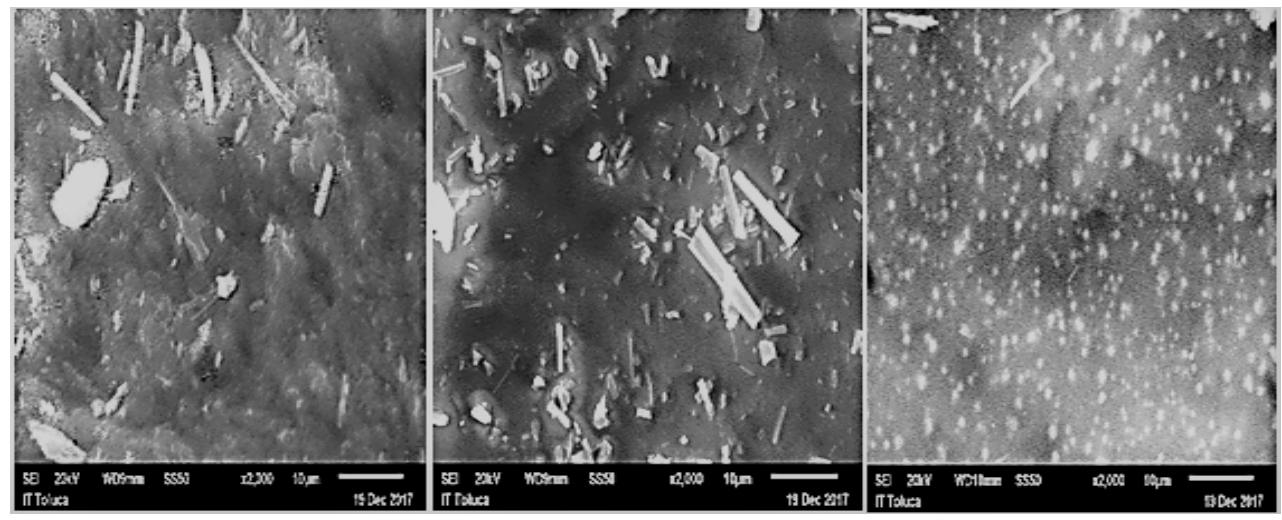

Figure 2. Micrographs from Scanning Electron Microscopy (SEM) of alginate-Collagen (SA-CO), Alginate-Arabic gum (SA-AG) and Alginate-Gelatin (SA-GE) capsules surface; from left to right, loaded with $\mathrm{f} 4$ peptide fraction. 
Micrographs show surfaces from capsules without fissures and with some clusters of material, evidencing the adequate dispersion of fillers onto SA capsule; cracks and porous present in these images are characteristic of SA, due to the crosslinking process with calcium chloride. Particularly, the following differences were observed in the surface of the capsules.

SA-GE and SA-CO presented a more homogeneous surface without the presence of holes; whereas, SA-AG exhibited a heterogeneous surface with the possible formation of some pores in the structure, confirming the results of pore dimensions showed in Table 1 for each composite capsule.

It was also possible to observe the peptide $\mathrm{f} 4$ fraction on the capsules; a higher amount of peptides was evident in the surface area from SA-AG and SA-CO, indicating the homogeneous distribution of peptides throughout materials. Nevertheless, in SA-GE capsules, peptides were not visible; therefore, complex formations of $\mathrm{f} 4$ and GE could give a possible explanation to this result.

The principal applications of SA, CO, AG, and GE as delivery materials have been previously reported [26]. They have been often studied as individual carriers of active substances as drugs and food ingredients; properties of gastro retentive dosage and the augment of the gastric residence time into the delivery system have been confirmed in these reports [27,28].

Characteristics of dispersion, assembly, and biocompatibility of SA have also been tailored via composite preparation. The SA composites have showed structures more resistant and less porous, enhancing the retention and the protection of different biomolecules [7]. However, its application in synthesized SA-CO, SA-AG, and SA-GE capsules of whey peptides is little known in the literature. Therefore, the obtained information can be valuable in the area of production and encapsulation of whey peptides.

Previous works about whey peptides encapsulation have indicated the benefits that offer different carrier systems in the protection and releasing of peptides [4,7]. Mainly some polysaccharides and proteins as encapsulation materials (capsules and particles) have been utilized to inhibit the bitter taste and reduce the hygroscopicity of peptides [7]. However, it has also exposed that the encapsulating system types, encapsulating material, and peptides affect encapsulation efficiency. Peptides interaction and their molecular mass can cause low retention and releasing of the active peptides. Zhang et al. [28] tested the preparation of $\mathrm{SA}$ at different $\mathrm{pH}$ values $(3,5$, and 7$)$, which influences in the protein-alginate electrostatic interactions, and thus affects the release of peptides.

Other excellent carriers of whey protein hydrolysates were described in Kavianina et al. [11]. They utilized microparticles of maltodextrin or maltodextrin/ $\beta$-cyclodextrin, enhancing the hygroscopic properties of whey peptides; the stability and activity was tested. In addition, these materials did not present interactions with peptides and they did not exhibit negative effects on their biological activity. Mohan et al. [13] tested soy lecithin-derived nanoliposomes as encapsulating systems of whey peptides to analyze the influence of the molecular weight range in peptides encapsulation efficiency. They showed that the different distribution of peptides between the polar surface/core and the hydrophobic bilayer of the liposomes affects the encapsulation efficiency of whey peptides.

\subsection{Simulated Gastrointestinal Digestion of ACE-Inhibitory Peptide Fractions}

Table 2 shows the results of the release kinetics of $f 4$ peptide fraction during simulated gastric phases from 50 capsules (approximately $4 \mathrm{mg} / \mathrm{L}$ of protein and $78 \%$ of initial ACE). Data from gastric phases of non-encapsulated f4 peptide fraction is also presented as a control analysis.

Given the condition of the non-encapsulated f4, its digestion showed the highest release of peptides during the oral phase, with a small ACE inhibition percentage. Meanwhile, its digest phase revealed a lower amount of released peptides, as well as a reduced ACE activity, exposing the probable production of inactive peptides by enzymatic degradation in gastric fluid, as it was expected. The instability and fast degradation of free peptide fractions have been exposed in previous reports [1,5].

The digestion of encapsulated $\mathrm{f} 4$ fraction displayed different results. An optimal dose and a controlled release were mainly obtained in the case of SA-CO and SA-AG capsules, since peptides 
were released during the three phases of digestion. The highest ratio of the released peptides and ACE inhibition percentage were found as follows: gastric phase $>$ oral phase $>$ duodenal phase.

Specifically, peptides from SA-AG capsules incremented their ACE activity (85\%) after digestion, with respect to the initial ACE activity (74\%); the optimal release and hydrolysis of $\mathrm{f} 4$ fraction can be attributed to this result. On the other hand, ACE activity from peptides from SA-CO and SA-AG capsules, 50\% and 70\% respectively, was lower than SA-GE; however, their activity was not comparable with ACE activity from peptides from the non-encapsulated $\mathrm{f} 4$ fraction $(<20 \%)$, revealing for each encapsulated material, an effective protection and a higher release efficiency of $\mathrm{f} 4$.

Table 2. Release kinetics of gastric phases of $f 4$ peptide fraction from capsules SA-CO, SA-AG, SA-GEm and non-encapsulated peptides.

\begin{tabular}{|c|c|c|c|c|c|c|c|c|c|}
\hline \multirow{3}{*}{$\begin{array}{l}\text { Gastric } \\
\text { Phase }\end{array}$} & \multirow{3}{*}{$\begin{array}{l}\text { Time } \\
(\mathrm{min})\end{array}$} & \multicolumn{4}{|c|}{ Ratio of Released Peptides (mg/L) } & \multicolumn{4}{|c|}{ ACE Inhibition (\%) } \\
\hline & & \multicolumn{3}{|c|}{ Loaded Capsules of $\mathrm{f} 4$} & \multirow{2}{*}{$\begin{array}{c}\text { Non-encapsulated } \\
\mathrm{f} 4\end{array}$} & \multicolumn{3}{|c|}{ Loaded Capsules of $\mathrm{f} 4$} & \multirow{2}{*}{$\begin{array}{c}\text { Non-encapsulated } \\
\text { f4 }\end{array}$} \\
\hline & & SA-CO & SA-AG & SA-GE & & SA-CO & SA-AG & SA-GE & \\
\hline Oral & 10 & 1.5 & 0.5 & 1.0 & 2.3 & 25.3 & 9.6 & 18.6 & 15.2 \\
\hline Gastric & 120 & 2.1 & 2.7 & 1.6 & 0.8 & 39.5 & 57.4 & 30.3 & 2.7 \\
\hline Duodenal & 120 & 0.3 & 0.6 & 1.4 & 0.1 & 9.5 & 20.4 & 5.0 & 0.0 \\
\hline Total & 250 & 3.9 & 3.8 & 4.0 & 3.8 & 74.3 & 86.4 & 53.9 & 17.9 \\
\hline
\end{tabular}

The degradation details on the behavior of these capsules during the digestive process are described in Figure 3. A primary degradation of the encapsulated filler materials was detected in the gastric step; capsules erosion with filler materials $\mathrm{CO}, \mathrm{AG}$, and GE were observed during the gastrointestinal phase; whereas, SA capsules did not suffer any change. Thus, the release of peptides was attributed to the diffusion of $\mathrm{f} 4$ fraction, as well as materials erosion and dissolution. Hence, the contained peptides corresponded to both, $\mathrm{f} 4$ and products of their hydrolysis or degradation by gastric enzymes and $\mathrm{pH}$ conditions. This fact could explain the differences of ACE inhibition percentage from the capsules; peptides from SA-CO and SA-GE exhibited a lower ACE \% than SA-AG. The reduced ACE \% was associated to inactive peptides, due to digestive enzyme attack and to the release of degraded amino acid sequences. The structure of $\mathrm{f} 4$ fraction could also suffer some change from its original form, releasing inactive peptide fractions. In addition, the formation of complexes, predominantly f4-GE, could explain the low ACE activity of peptides from SA-GE.

In the case of the oral phase, the released peptides could be refereed to peptides diffused from $\mathrm{f} 4$ fraction, contained in the capsule surface; in addition, a possible slight degradation of fillers could also be presented. Meanwhile, the presence of peptides in the duodenal phase could be attributed to the existence of $\mathrm{f} 4$ fraction, peptides from $\mathrm{f} 4$, and degraded $\mathrm{CO}$ or GE and their peptides with lower activity.

At this point, data from the digestion of $\mathrm{f} 4$ fraction contained in SA-GE capsules are also remarkable. In this case, the ACE inhibition \% was lower than the released peptide sequences from SA-CO and SA-AG capsules. This result was linked to the strong interactions between peptides from $\mathrm{f} 4 \mathrm{fraction}$ and SA-GE, still in the duodenal phase; assuming the formation of complexes f4-GE and thus, a reduced hydrolysis and releasing of active peptides, as well as, possible reactions of $\mathrm{f} 4$ with the carboxylic acid groups of the SA, which may result in protein denaturation.

In the case of the digestion of SA-AG capsules, the release of a greater amount of ACE active peptides was associated to the integral retention of $\mathrm{f} 4$ and its optimal release in the gastric phase to produce active amino acid sequences. 


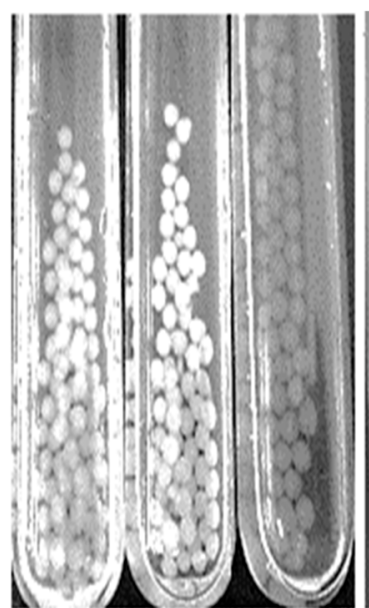

A

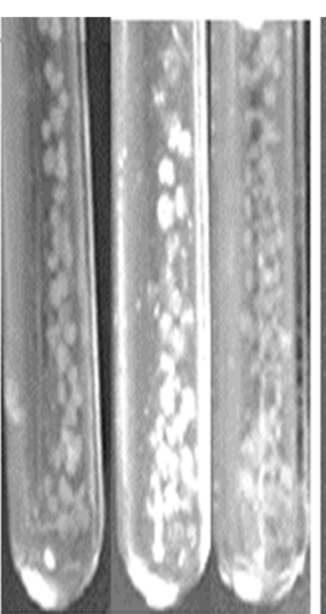

B

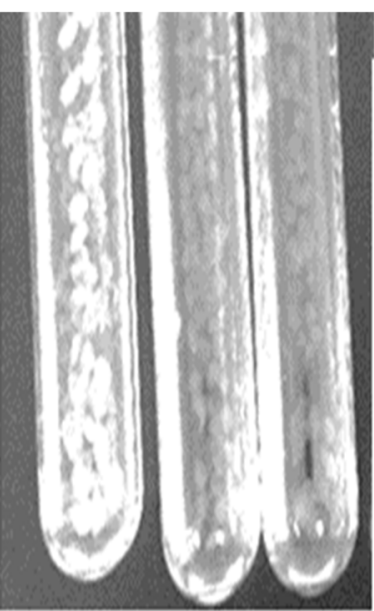

C

Figure 3. Images of f4 capsules during digest phases: (A) SA-AG, (B) SA-CO, and (C) SA-GE. From left to right: initial capsules, at the end of oral phase, at the end of gastric phase.

\subsection{Amino Acid Sequences from Released Peptides in Simulated Gastrointestinal Digestion from Encapsulated} f4 Fraction

Relevant information on released amino acid sequences from f4 (non-encapsulated and encapsulated samples) was obtained before and after their digestion.

In order to illustrate these results, Figure 4 shows images of MS/MS fragmentation spectrum of the studied samples as (A) a fraction from undigested and non-encapsulated f4; (B) an obtained fraction from a digested SA-AG capsules, which corresponds to the gastric phase; (C) an obtained fraction from a digested SA-AG from the duodenal phase.

Note that Figure 4A shows the spectrum of a fraction with an approximate charge on $m / z=1195$, with a prominent ion at $m / z=717.35$, an intensity of $1.6 \times 10^{4}$ and with two generated fragments-considering peptides counts for intensities above 5000 units for their identification. Figure $4 \mathrm{~B}$ displays a similar spectrum of the same fraction $(\mathrm{m} / \mathrm{z}=1195)$. In this case, an identical prominent ion is observed at 717.36; but it is noteworthy that the intensity of the base peak was greater around $4.2 \times 10^{4}$; thus, the mass region of the spectrum was normalized, according to this ion. Consequently, the released fragments were similar to the spectrum of Figure 4A; however, another ion fragment at $m / z=429.31$ could be observed. This was an indication of the different $f 4$ sequences obtained after the digestion of SA-AG capsules. Meanwhile, Figure 4C shows the spectrum of the same fraction; however, two prominent ions were found at $m / z=619.38$ and 371.22 (above 5000 units of intensity). It is worth mentioning the presence of the recognized ion $(m / z=717.34)$, but with a lower intensity value. These results are probably attributed to the digested fraction in the duodenal phase.

Sequences of released fragments from samples relatives to $f 4$ are presented in Table 3. The data include amino acid sequences from digest phases of non-encapsulated and encapsulated f4 into SA-CO, SA-AG, and SA-GE capsules in simulated conditions. Data also contains undigested free (non-encapsulated) sample $\mathrm{f} 4$ and digested free $\mathrm{f} 4$ as data control. According to MS/MS fragmentation of $\mathrm{f} 4$, some fractions matched the protein databases. Identified amino acid sequences from $\mathrm{f} 4$ peptides and their protein origin are presented according to the data from MS spectra against UniProt database. 

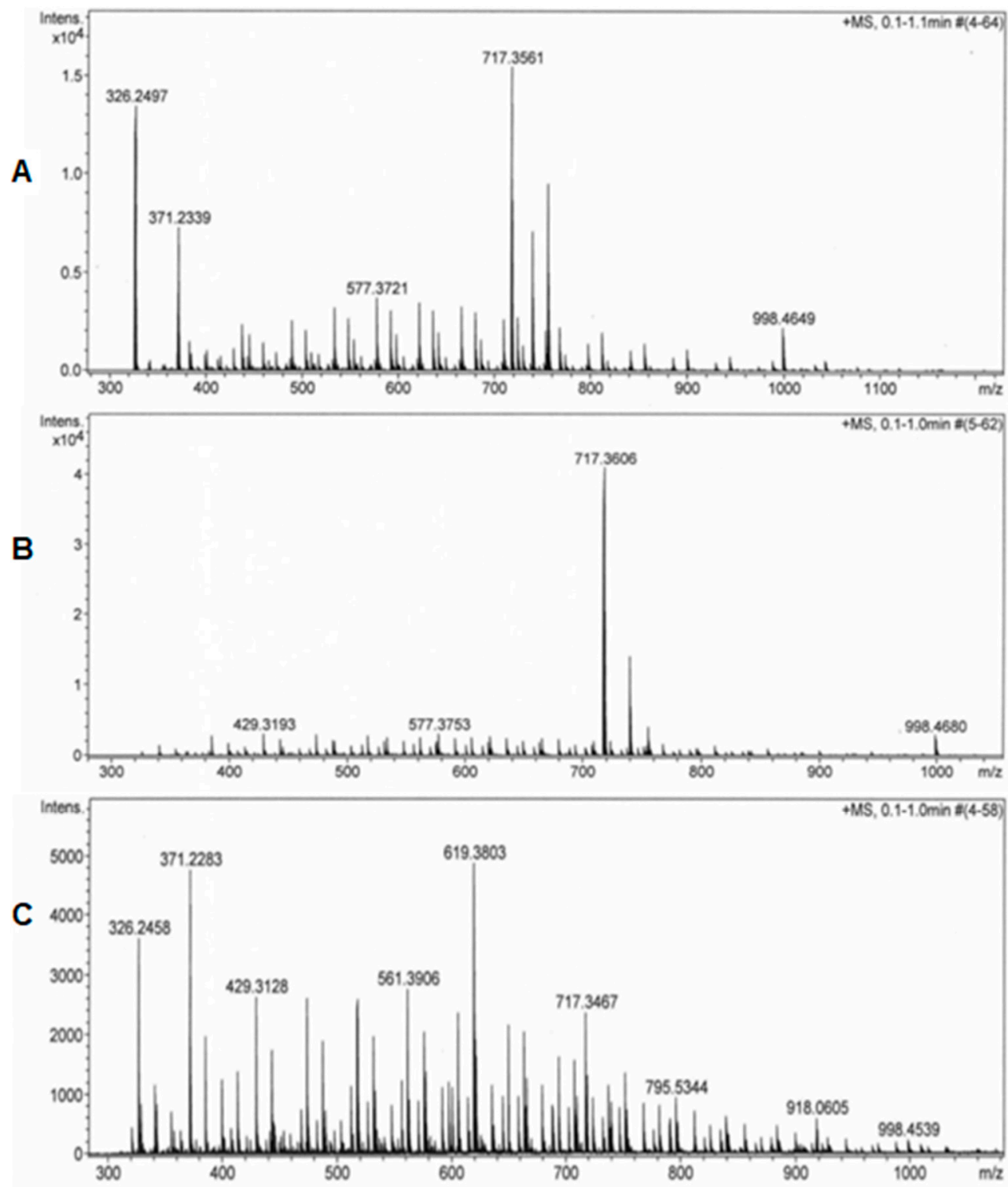

Figure 4. Mass/Mass (MS/MS) fragmentation spectrum of the studied samples as (A) a fraction from an undigested and non-encapsulated $\mathrm{f} 4$; (B) an obtained fraction from the digested SA-AG capsules corresponding to the gastric phase; (C) an obtained fraction from the digested SA-AG capsules from the duodenal phase.

As it can be observed, Table 3 shows that the identified sequences from $\mathrm{f} 4$ corresponded to residues of $\beta$-Lg and $\alpha$-La proteins, which is consistent with the previous work performed by Alvarado et al. [6], where it was demonstrated that the hydrolysis of WPC by B. subtilis for $6 \mathrm{~h}$, produced hydrolysates with high content of residues of these proteins. Other reports such as Kobayashi et al. [29], and Cicero and Borghi [30] also revealed that $\alpha$-La and $\beta$-Lg are the major sources of ACE-inhibitory peptides, and their activity may be comparable to that of captopril, an antihypertensive drug.

Table 3 also exposed that undigested and non-encapsulated f4 sample (first sample control, the more potent ACE inhibition fraction obtained from $\mathrm{WPCH}$ ) showed five amino acid sequences, all containing more than one hydrophobic and aromatics amino acid, which were identified as promoters of ACE inhibitory activity; such as valine $(\mathrm{V})$, glycine $(\mathrm{G})$, and proline $(\mathrm{P})$. Especially, fragments 1 and 5 contain $\mathrm{V}$ and $\mathrm{P}$ in the first and last sequence position. Positive charged amino acid, such as arginine (A) and lysine (L) at the C-terminal were also found in these structures (fractions 1, 3, and 5); they are also known as amino acid contributors of ACE inhibitory or antihypertensive effect [6]. Meanwhile the 
digestion of non-encapsulated $\mathrm{f} 4$ (second sample control) showed other amino acid residues. In this case, the gastric phase revealed three peptide sequences; displaying the effect of enzymatic action of the pepsin and the $\mathrm{pH}$ of gastric conditions in the degradation of precursors sequences from undigested f4. In addition, it is also possible to observe that no fragments were found in the duodenal phase; this result was associated to the complete degradation of these sequences in duodenal conditions, as was expected.

Table 3. Released fragment and identified sequences from fraction f4 during its digestion in simulated conditions.

\begin{tabular}{|c|c|c|c|c|c|c|}
\hline Sample Fraction $\mathrm{f} 4$ & $\begin{array}{l}\text { Digest } \\
\text { Phase }\end{array}$ & $\begin{array}{c}\text { Released } \\
\text { Fragments/Suggested } \\
\text { Sequence }\end{array}$ & $\begin{array}{l}\text { Identified } \\
\text { Sequence }\end{array}$ & $\begin{array}{l}\text { Experimental } \\
\text { Mass (Da) }\end{array}$ & $\begin{array}{l}\text { Theoretical } \\
\text { Mass (Da) }\end{array}$ & $\begin{array}{l}\text { Protein } \\
\text { Origin }\end{array}$ \\
\hline Non-encapsulated & Undigested & $\begin{array}{l}\text { 1. VNLSMYNGIAL } \\
\text { 2. ITPAVQMN } \\
\text { 3.TVVSAPNYTLR } \\
\text { 4. VAGTWY } \\
\text { 5.LMTGYPVILYP }\end{array}$ & VAGTWY & 695.4 & 695.2 & $\beta-\operatorname{Lg}$ \\
\hline Non-encapsulated & Gastric & $\begin{array}{l}\text { 1.SAPLR } \\
\text { 2.GTW } \\
\text { 3. TYV }\end{array}$ & SAPLR & 543.6 & 543.2 & $\beta-\operatorname{Lg}$ \\
\hline \multirow[t]{2}{*}{ Capsules SA-CO } & Gastric & $\begin{array}{l}\text { 1. VLDTDYK } \\
\text { 2. PAVQM } \\
\text { 3. TSGYPV }\end{array}$ & VLDTDYK & 852.6 & 852.4 & $\beta-\operatorname{Lg}$ \\
\hline & Duodenal & $\begin{array}{l}\text { 1.VDY } \\
\text { 2.KIDAL }\end{array}$ & KIDAL & 558.1 & 558.3 & $\beta-\operatorname{Lg}$ \\
\hline \multirow{2}{*}{ Capsules SA-AG } & Gastric & $\begin{array}{l}\text { 1. ENSAEP } \\
\text { 2. IPAVFK } \\
\text { 3. VAGTWY } \\
\text { 4. VSYT }\end{array}$ & $\begin{array}{l}\text { ENSAEP } \\
\text { IPAVFK } \\
\text { VAGTWY }\end{array}$ & $\begin{array}{l}645.5 \\
673.7 \\
695.4\end{array}$ & $\begin{array}{l}645.3 \\
673.4 \\
695.2\end{array}$ & $\beta-\operatorname{Lg}$ \\
\hline & Duodenal & $\begin{array}{l}\text { 1. VYT } \\
\text { 2. AMAASDE } \\
\text { 3. IPAVF } \\
\text { 4. MDSF }\end{array}$ & IPAVF & 545.5 & 545.3 & $\beta-\operatorname{Lg}$ \\
\hline \multirow{2}{*}{ Capsules SA-GE } & Gastric & $\begin{array}{l}\text { 1.DGFYELYAME } \\
\text { 2.VKTYMNATIK } \\
\text { 3. KIPAVF }\end{array}$ & KIPAVF & 673.1 & 673.4 & $\beta-\operatorname{Lg}$ \\
\hline & Duodenal & $\begin{array}{l}\text { 1. SAAGYT } \\
\text { 2. DFELY } \\
\text { 3. HTSGY }\end{array}$ & HTSGY & 563.2 & 563.2 & $\alpha-\mathrm{La}$ \\
\hline
\end{tabular}

In the case of the digestion of encapsulated f4, the presence of fragments after this process indicated that capsules were effective carriers, protectors, and release agents; this result was particularly outstanding in SA-AG and SA-CO capsules. Clearly, SA-AG obtained the highest amount of released peptides in both, gastric and duodenal phases, showing 4 peptide sequences in each phase respectively, but only 4 sequences were confirmed by matching the protein databases.

Other important results were obtained from SA-CO and SA-GE capsules. SA-CO showed three and two peptide sequences in the gastrointestinal and duodenal phase respectively. Meanwhile, SA-GE exposed three peptide sequences in each stage. However, only two sequences from SA-CO and SA- GE were identified in protein databases.

Summarizing, simulated digestion of encapsulated fraction 44 in SA-CO, SA-AG, and SA-GE exposed 19 peptide sequences. In parallel, only 11 peptide sequences were found in protein database and de novo searches.

Under these results, new peptides from whey $\mathrm{f} 4$ samples could be claimed. The digestion of $\mathrm{f} 4$ causes the releasing of peptides, showing new amino acid sequences. However, more studies are required to confirm the existence of novel peptides and also to define which of them are ultimately responsible for the potent antihypertensive activity. 
The difference in released sequences from $\mathrm{f} 4$ during capsules digestion were attributed to composite material properties SA-AG, SA-CO, and SA-GE; material interactions with peptides fragments; the formation of new peptides by hydrolysis of $\mathrm{f} 4$ during gastric and duodenal phase, and the formation of complex mixtures of peptides, due to hydrolysis of CO and GE, during the digestion of these capsules. Consequently, it was recognized, that only some digested fragments were derived from the precursors sequences from $\mathrm{f} 4$, indicating changes in the structure of the initial sequences from $\mathrm{f} 4$.

The obtained data were associated to different aspects that affected sequences isolation and identification during the chromatographic analysis, such as formation of complex mixtures of peptides, difficulty in sequencing peptides, and peptide fragment interactions with $\mathrm{CO}$ and GE which affected peptide recovery. Possible peptide degradation and the formation of new and different fragments could also be exposed, due to $\mathrm{CO}$ and GE that have a protein origin.

Previous reports have also established that GE particles show complex chromatograms after the digested samples precluding the identification of peptides from the hydrolysate [16]. Their results also exposed that the gelatin carrier released 58 peptides from encapsulated whey active fractions; however, after particles disruption, 13 peptides were not identified, associating this result to peptide-matrix interactions.

Comparable active sequences from whey proteins have also been described in other studies. For example, Tavares et al. [31] identified three novel peptides with ACE-inhibitory effect, corresponding to $\alpha$-La $\mathrm{f}(16-26), \alpha$-La $\mathrm{f}(97-104)$, and $\beta$-Lg f(33-42)-with KGYGGVSLPEW, KVGINYW, and DAQSAPLRVY sequences, each one showing $\mathrm{IC}_{50}$ values like $0.80,25.2$, and $13.0 \mu \mathrm{g} / \mathrm{mL}$. On the other side, Ibrahim et al. [32] identified one potent ACE inhibitory peptide from $\beta$ - $\operatorname{Lg}$ (residues 113-122) with PEQSLACQCL sequence, exhibiting $\mathrm{IC}_{50}$ values of $4.45 \mu \mathrm{M}$.

\section{Conclusions}

In this study, antihypertensive peptide fraction (f4) with 74\% of ACE inhibitory activity from whey protein hydrolysate was encapsulated using composite materials SA-CO, SA-AG, and SA-GE as capsules, in order to extend peptides activity and to control its release in the gastrointestinal phase.

Besides, the studied capsules presented a high value ( $85 \%-95 \%)$ of encapsulation efficiency; from them, SA-AG achieved the highest level, followed by SA-CO and SA-GE.

The digestion of encapsulate peptides revealed an optimal dose and release control; it was mainly obtained by SA-AG and SA-CO capsules, since peptides were released during the three phases of digestion. The highest ratio of released peptides and ACE inhibition percentage (\%) was found as follows: gastric phase $>$ oral phase $>$ duodenal phase. In addition, peptides from SA-AG incremented their ACE activity (up to 85\%), from their initial ACE activity; whereas, peptides from SA-CO and SA-GE $(50 \%-70 \%)$ was lower than SA-AG. The reduced ACE $\%$ of peptides from SA-GE was associated to the inactive peptides, due to the digestive enzyme attack and to the release of degraded amino acid sequences. The structure of $\mathrm{f} 4$ could also suffer some changes from its original form, releasing inactive peptide fractions. The last results depended on materials properties, such as capacity of entrapment, binding abilities, and interactions with peptide fractions.

In the case of sequences identification, non-encapsulated and undigested antihypertensive peptides revealed five peptide sequences (peptide $>5000$ intensity units); while, encapsulated peptides showed different sequences at the end of digestion phases; however, only some sequences were confirmed by matching the protein databases; consequently, new peptides could be obtained from whey fraction. Nonetheless, more studies are required to claim these peptides and also to define which of them are ultimately responsible for the potent antihypertensive activity.

The obtainment of cleaner spectrums was also vital to get a successful way a sequencing de novo. Similarly, more chromatographic studies are required to obtain precise results about peptide sequences; the challenge to match a unique peptide sequence to the targeted molecular mass.

Additional experiments are similarly essential to declare that the encapsulation procedure did not affect the initial fraction, since complex mixtures formation and peptide fragment interactions with $\mathrm{CO}$ 
and GE could affect peptide recovery. Possible peptide degradation and the formation of new and different fragments could also be discovered, since CO and GE are of protein origin.

Another challenge was the test validating the effect of these novel peptides, because they should be verified in vivo. In addition, studies about peptides with $<5000$ units of intensity could also be exposed to explain the ACE-inhibitory effects from $\mathrm{f} 4$ samples, thus complementing this research. Additional experiments are similarly essential to declare that the encapsulation procedure did not affect the initial fractions from $\mathrm{f} 4$.

Author Contributions: Conceptualization, C.M. and F.R.; Methodology, Y.A. and M.d.C.D.; Software, Y.A.; Validation, C.M. and Y.A.; Formal Analysis, C.M., F.R. and Y.A.; Investigation, Y.A.; Resources, C.M.; Data Curation, J.I.; Writing-Original Draft Preparation, C.M. and Y.A.; Writing-Review \& Editing, C.M. and J.I.; Supervision, C.M.; Project Administration, C.M. and Y.A.; Funding Acquisition, C.M. and Y.A.

Funding: We thank National Technologic of Mexico for its financial support (TecNM, projects 2016, 2018, 5940.16-P; 6834.18-P).

Conflicts of Interest: The authors declare no conflicts of interest.

\section{References}

1. Muro, U.C.; Álvarez, F.R.; Riera, R.F.; Arana, C.A.; Téllez, J.A. Production and functionality of active peptides from milk. Food Sci. Technol. Int. 2011, 17, 293-317. [CrossRef] [PubMed]

2. Dullius, A.; Goettert, M.I.; de Souza, C.F.V. Whey protein hydrolysates as a source of bioactive peptides for functional foods-Biotechnological facilitation of industrial scale-up. J. Funct. Foods 2018, 42, 58-74. [CrossRef]

3. Rocha, G.F.; Kise, F.; Rosso, A.M.; Parisi, M.G. Potential antioxidant peptides produced from whey hydrolysis with an immobilized aspartic protease from Salpichroa origanifolia fruits. Food Chem. 2017, 237, 350-355. [CrossRef]

4. Muro, U.C.; Riera, R.F.; Alvarado, P.Y. Encapsulation of whey proteins. In Whey Proteins Functional Properties Production and Health Benefits; Wyatt, M., Ed.; Nova Publishers: New York, NY, USA, 2014; pp. 75-116.

5. Alvarado, P.Y.; Muro, U.C.; Martínez, J.; Nava, M.; Rodríguez, F. Functionalized polymers for enhance oral bioavailability of sensitive molecules. Polymers 2016, 8, 1-22.

6. Alvarado, P.Y.; Muro, U.C.; Cerda, A.M.; Sánchez, J.A.; Rodríguez, F.R. Antihypertensive and Antioxidant Properties from Whey Protein Hydrolysates Produced by Encapsulated Bacillus subtilis Cells. Int. J. Pep. Res. Ther. 2018, 25, 1-9. [CrossRef]

7. Mohan, A.; Rajendran, S.R.; He, Q.S.; Bazinet, L.; Udenigwe, C.C. Encapsulation of food protein hydrolysates and peptides: A review. RSC Adv. 2015, 5, 79270-79278. [CrossRef]

8. Ray, S.; Raychaudhuri, U.; Chakraborty, R. An overview of encapsulation of active compounds used in food products by drying technology. Food Biosci. 2016, 13, 76-83. [CrossRef]

9. Yu, C.Y.; Yin, B.C.; Zhang, W.; Cheng, S.X.; Zhang, X.Z.; Zhuo, R.X. Composite microparticle drug delivery systems based on chitosan, alginate and pectin with improved $\mathrm{pH}$-sensitive drug release property. Coll. Surf. B 2009, 68, 245-249. [CrossRef]

10. Yang, S.; Mao, X.Y.; Li, F.F.; Zhang, D.; Leng, X.J.; Ren, F.Z.; Teng, G.X. The improving effect of spray-drying encapsulation process on the bitter taste and stability of whey protein hydrolysate. Eur. Food Res. Technol. 2012, 235, 91-97. [CrossRef]

11. Kavianinia, I.; Plieger, P.G.; Kandile, N.G.; Harding, D.R. In vitro evaluation of spray-dried chitosan microspheres crosslinked with pyromellitic dianhydride for oral colon-specific delivery of protein drugs. J. Appl. Polym. Sci. 2014, 131, 1-13. [CrossRef]

12. Ma, J.J.; Mao, X.Y.; Wang, Q.; Yang, S.; Zhang, D.; Chen, S.W.; Li, Y.H. Effect of spray drying and freeze drying on the immunomodulatory activity, bitter taste and hygroscopicity of hydrolysate derived from whey protein concentrate. LWT Food Sci. Technol. 2014, 56, 296-302. [CrossRef]

13. Mohan, A.; McClements, D.J.; Udenigwe, C.C. Encapsulation of bioactive whey peptides in soy lecithin-derived nanoliposomes: Influence of peptide molecular weight. Food Chem. 2016, 213, 143-148. [CrossRef] 
14. Zhang, Q.T.; Tu, Z.C.; Xiao, H.; Wang, H.; Huang, X.Q.; Liu, G.X.; Lin, D.R. Influence of ultrasonic treatment on the structure and emulsifying properties of peanut protein isolate. Food Bioprod. Process. 2014, 92, 30-37. [CrossRef]

15. Kostadinova, A.I.; Middelburg, J.; Ciulla, M.; Garssen, J.; Hennink, W.E.; Knippels, L.M.; Willemsen, L.E. PLGA nanoparticles loaded with beta-lactoglobulin-derived peptides modulate mucosal immunity and may facilitate cow's milk allergy prevention. Eur. J. Pharmacol. 2018, 818, 211-220. [CrossRef]

16. Gomez-Mascaraque, L.G.; Morfin, R.C.; Pérez-Masiá, R.; Sanchez, G.; Lopez-Rubio, A. Optimization of electrospraying conditions for the microencapsulation of probiotics and evaluation of their resistance during storage and in-vitro digestion. LWT Food Sci. Technol. 2016, 69, 438-446. [CrossRef]

17. Bokkhim, H.; Bansal, N.; Grøndahl, L.; Bhandari, B. In-vitro digestion of different forms of bovine lactoferrin encapsulated in alginate micro-gel particles. Food Hydrocoll. 2016, 52, 231-242. [CrossRef]

18. Giroux, H.J.; Robitaille, G.; Britten, M. Controlled release of casein-derived peptides in the gastrointestinal environment by encapsulation in water-in-oil-in-water double emulsions. LWT Food Sci. Technol. 2016, 69, 225-232. [CrossRef]

19. Cushman, D.W.; Cheung, H.S. Spectrophotometric assay and properties of the angiotensin-converting enzyme of rabbit lung. Biochem. Pharmacol. 1971, 20, 1637-1648. [CrossRef]

20. Minekus, M.; Alminger, M.; Alvito, P.; Ballance, S.; Bohn, T.; Bourlieu, C.; Dufour, C. A standardized static in vitro digestion method suitable for food-An international consensus. Food Funct. 2014, 5, 1113-1124. [CrossRef] [PubMed]

21. UniProt database. The UniProt Consortium UniProt: The Universal Protein Knowledgebase Nucleic Acids Res. 45: D158-D169, 2019. Available online: http://www.uniprot.org/peptidesearch/ (accessed on 19 September 2018).

22. Le Maux, S.; Nongonierma, A.B.; FitzGerald, R.J. Improved short peptide identification using HILIC-MS/MS: Retention time prediction model based on the impact of amino acid position in the peptide sequence. Food Chem. 2015, 173, 847-854. [CrossRef] [PubMed]

23. Jemil, I.; Abdelhedi, O.; Nasri, R.; Mora, L.; Jridi, M.; Aristoy, M.C.; Nasri, M. Novel bioactive peptides from enzymatic hydrolysate of Sardinelle (Sardinella aurita) muscle proteins hydrolysed by Bacillus subtilis A26 proteases. Food Res. Int. 2017, 100, 121-133. [CrossRef] [PubMed]

24. Peanparkdee, M.; Yamauchi, R.; Iwamoto, S. Stability of bioactive compounds from Thai Riceberry bran extract encapsulated within gelatin matrix during in vitro gastrointestinal digestion. Coll. Surf. A Physicochem. Eng. Aspects 2018, 546, 136-142. [CrossRef]

25. Wu, J.; Aluko, R.; Nakai, S. Structural Requirements of Angiotensin I-Converting Enzyme Inhibitory Peptides: Quantitative Structure-Activity Relationship Study of Di- and Tripeptides. J. Agric. Food Chem. 2006, 4, 732-738. [CrossRef] [PubMed]

26. Pal, K.; Paulson, T.; Rousseau, D. Biopolymers in controlled-release delivery systems. In Modern Biopolymer Science; Kasapis, S., Norton, I.T., Ubbink, J.B., Eds.; Academic Press: Philadelphia, PA, USA, 2009; pp. 519-557.

27. Groening, R.; Bensmann, H. High frequency controlled capsules with integrated gas producing cells. Eur. J. Pharm. Biophar. 2009, 72, 282-284. [CrossRef]

28. Zhang, Z.; Zhang, R.; Zou, L.; McClements, D.J. Protein encapsulation in alginate hydrogel beads: Effect of $\mathrm{pH}$ on microgel stability, protein retention and protein release. Food Hydrocoll. 2016, 58, 308-315. [CrossRef]

29. Kobayashi, Y.; Yamauchi, T.; Katsuda, T.; Yamaji, H.; Katoh, S. Angiotensin-I converting enzyme (ACE) inhibitory mechanism of tripeptides containing aromatic residues. J. Biosci. Bioeng. 2008, 106, 310-312. [CrossRef]

30. Cicero, A.F.; Borghi, C. Evidence of clinically relevant efficacy for dietary supplements and nutraceuticals. Curr. Hypertens. Rep. 2013, 15, 260-267. [CrossRef] [PubMed]

31. Tavares, T.G.; Monteiro, K.M.; Possenti, A.; Pintado, M.E.; Carvalho, J.E.; Malcata, F. X Antiulcerogenic activity of peptide concentrates obtained from hydrolysis of whey proteins by proteases from Cynara cardunculus. Int. Dairy J. 2011, 21, 934-939. [CrossRef]

32. Ibrahim, H.R.; Ahmed, A.S.; Miyata, T. Novel angiotensin-converting enzyme inhibitory peptides from caseins and whey proteins of goat milk. J. Adv. Res. 2017, 8, 63-71. [CrossRef] [PubMed]

(C) 2019 by the authors. Licensee MDPI, Basel, Switzerland. This article is an open access article distributed under the terms and conditions of the Creative Commons Attribution (CC BY) license (http://creativecommons.org/licenses/by/4.0/). 